\title{
ENTRE 0 DEVIR E A TRANSFORMAÇÃO: REFLEXÕES ANTROPOLÓGICAS ENTRE OS MBYÁ-GUARANİ NO CONE SUL
}

BRUNO NASCIMENTO HUYER ${ }^{1}$

$U F S C$

\begin{abstract}
RESUMO: Este trabalho é resultado de pesquisas antropológicas realizadas entre os MbyáGuarani na Região Sul do Brasil e norte da Argentina. Baseando-se no método etnográfico, a pesquisa buscou noções nativas de relação com as alteridades, humanas e não humanas. Para este fim, o trabalho dividiu-se em duas partes: a primeira centra-se na análise de um homem que acabou transformando-se em onça ao desejar em excesso o sangue das carnes cruas. A segunda parte busca apresentar como essa transformação pode informar a relação dos Mbyá com os não indígenas. Para isso, parte-se da história de um mbyá que, enfeitiçado por uma mulher não indígena, casa-se com ela e passa a morar na cidade, abandonando sua família. Essas duas histórias parecem sugerir que, do mesmo modo que o Mbyá motivado pelo desejo de carne (crua) transforma-se em onça e abandona seus parentes para viver na floresta, há os Guarani que, enfeitiçados pela carne (nиa) dos não indígenas, abandonam suas famílias para viver nas cidades. Conclui-se que a relação com outrem necessita ser praticada com os cuidados de uma boa distância para não cair no risco da mestiçagem.
\end{abstract}

PALAVRAS-CHAVE: mbyá-guarani; transformação; corpo; antimestiçagem.

ABSTRACT: This paper is the result of anthropological research carried out among the MbyáGuarani in Southern Brazil and Northern Argentina. Based on the ethnographic method, the research pursued native notions of relationship to otherness, human and nonhuman. To this end, the work was divided into two parts: the first focuses on the analysis of a man who ended up becoming a jaguar because of his excessive wish for raw meat. The second part aims to show how this transformation can inform about the relationship between the Mbya and non-indigenous people. In order to do so, the paper presented a story of a Mbya bewitched by a non-indigenous woman -- he marries her and goes to live in the city, abandoning his family. These two stories seem to suggest that the same way as the Mbya motivated by the desire of (raw) meat becomes a jaguar and abandons his family to live in the forest, there are the Guarani who, eager for the (naked) meat of non-indigenous, abandon their families to live in cities. Therefore, the relationship with others needs to be practiced from good distance to avoid falling into the trap of miscegenation.

KEYWORDS: Mbyá-Guarani; transformation; body; anti-miscegenation.

\footnotetext{
${ }^{1}$ Bacharel e licenciado em Ciências Sociais pela UFRGS, mestrando no Programa de Pós-graduação em Antropologia Social da UFSC, bolsista CAPES com pesquisa em desenvolvimento entre os Mbyá-guarani. E-mail: brunonhuyer@gmail.com .
} 


\section{Kanuto e a transformação}

Kanuto era um mbyá-guarani que morava na aldeia indígena de Tamanduá, na Argentina. Ele era reconhecido por todos como um ótimo caçador, pois sempre era muito bem sucedido em suas expedições. Foi por volta dos anos 1970 que essas caçadas passaram a aumentar de frequência e a gerar preocupações em seus familiares, principalmente porque sua ausência cada vez mais se prolongava. Quando questionado por essas expedições serem cada vez mais largas e por sempre ir sozinho, Kanuto se enfurecia, fazendo-o abandonar sua família para mais saídas ao mato em busca de sossego.

Sua mulher começou a estranhar suas atitudes ao perceber que sua paixão pelas carnes caçadas estava um pouco descontrolada. Ela percebia que as caças que seu marido trazia estavam muitas vezes já comidas, sem que tivessem sido assadas. Seu prazer pela carne malassada também aumentava progressivamente, fazendo com que sua esposa começasse a sentir receio de que Kanuto poderia estar se transformando em outro.

As preocupações de sua companheira viriam por fim a se confirmar. Enquanto compartilhavam a cama em meio à madrugada de uma rigorosa noite de inverno em Tamanduá, Kanuto se levantou e, indo em direção à porta de onde viviam, começou a conversar com alguns seres que rondavam a casa. Sua mulher, ainda meio dormida, não conseguia entender o que Kanuto falava. Nas madrugadas Kanuto passou a conversar com outros animais da floresta, conversava com esses outros como quem conversava com seus parentes.

Passadas algumas semanas de noites agitadas, Kanuto saiu para mais uma expedição de caça, mas dessa vez não voltou da mesma forma. Sua mulher, muito preocupada e com um pressentimento ruim por mais um sumiço repentino de Kanuto, avisa o avô (xeramoi) e grande xamã (karaí) da aldeia sobre os acontecimentos anteriores. Falou tudo: que seu marido ficava cada vez mais sozinho, sobre suas desconfianças quanto às carnes mal-assadas e sobre as conversas nas madrugadas. Depois de ouvir todas as histórias, o karaí vai ao mato com mais alguns companheiros para procurar Kanuto, já temendo por sua possível transformação (ojepotá). Depois de dias de procura, 
intercaladas com consultas às divindades, acharam-no suspenso em uma árvore com uma corda enrolada em seu pescoço. Isso fazia parte de sua estratégia em completar a metamorfose a partir da morte enquanto Guarani. Também notaram que seu braço e peito estavam queimados, uma evidência da ação de Tupã através de um raio lançado em Kanuto.

O corpo de Kanuto já não aparentava o mesmo. Metade de seu corpo era onça, suas pernas já não eram mais eretas e estavam transformadas em patas, seu tronco curvado na posição característica dos felinos. Sua pele também estava diferente, as manchas características das xivy (onças) apareciam, principalmente na parte inferior de seu corpo. O grande xeramoi trouxe Kanuto à aldeia aparentemente morto. Aparentemente, pois apesar de não aparecerem batimentos cardíacos, nem qualquer sinal de vida, Kanuto conservava um "fio de vida". Esses seres em processo transformacional conservam uma pequena intensidade de vida que possibilita a completa transformação, condição essa que acaba enganando os Mbyá desavisados, que enterram os ojepotá ${ }^{2}$ ainda "vivos", possibilitando a esses "mutantes" uma espécie de renascimento debaixo da terra. Sabendo do risco do ojepotá, que ao aparentar estar morto revira-se debaixo da terra para voltar ao mundo totalmente transformado, o xeramoi tentou cravar uma lança no peito de Kanuto. $\mathrm{Na}$ primeira tentativa a lança perdeu todo o seu fio, Kanuto já não tinha mais pele humana, possuía o couro grosso de uma onça. Somente na terceira lança que o couro de Kanuto foi perfurado e sua morte, enfim, confirmada, garantindo a segurança da aldeia (Caderno de campo, 17.11.2009).

As reflexões aqui presentes pretendem sugerir como a história da transformação corporal de uma pessoa (mbyá) em uma onça pode lançar luz às relações que os Mbyá-Guarani3 praticam com os não indígenas. Neste caso, conforme será defendido, o entendimento sobre o corpo e sua instabilidade crônica (VILAÇA, 2005) que emergem da história de Kanuto perpassam o esquema teórico-relacional da maestria-domínio (FAUSTO, 2008), e vão permitir compreender certos aspectos da relação

\footnotetext{
2 Transformado/transformação: no decorrer deste trabalho ficará mais claro todos os elementos que envolvem essa transformação.

${ }^{3}$ Os Guarani são descritos na literatura etnológica como os grupos indígenas que falam o idioma de mesmo nome, pertencente à família Tupi-Guarani do tronco linguístico Tupi. Seguindo uma classificação linguística, a partir desse idioma se ramificariam diferentes dialetos: Mbyá, Nhandeva/Xiripá e Kaiowá estão entre os grupos mais numerosos demograficamente.
} 
entre os Mbyá e os brancos ${ }^{4}$. O que está em jogo é como o entendimento sobre Outros parte de lógicas internas aos grupos indígenas - lógicas essas anteriores à chegada dos brancos e a partir das quais eles passam a ser incorporados 5 (LÉVI-STRAUSS, 1993).

Este trabalho tem como base experiências de convívio junto a algumas famílias mbyá-guarani que transitaram por diferentes aldeias desde a região de Misiones, na Argentina, passando pelo interior - na região das reduções jesuíticas de São Miguel Arcanjo - até o litoral do Rio Grande do Sul, próximo a Viamão. Tais deslocamentos estão relacionados com questões que envolvem o jeguatá6 e os perigos intrínsecos das relações sociais (como veremos mais adiante). Apesar de reconhecer a importância dos nomes para os Mbyá, resolvi trocá-los por nomes fictícios, principalmente para que as identidades sejam preservadas em meio ao atual cenário político brasileiro.

A história de Kanuto foi contada a mim no ano de 2009, quando participava de um projeto que discutia a mobilidade guarani através dos diferentes países do Cone Sul americano. O projeto visava reconhecer essa mobilidade transnacional para que os países pudessem adequar suas políticas públicas a fim de garantir o direito dos Guarani ao trânsito em seu macro-território. Através dos pesquisadores vinculados ao Núcleo de Antropologia das Sociedades Indígenas e Tradicionais (NIT) e ao Laboratório de Arqueologia e Etnologia (LAE), ambos da Universidade Federal do Rio Grande do Sul (UFRGS), nos dividimos em duas aldeias localizadas no estado do Rio Grande do Sul, Brasil, para pensar essa mobilidade transnacional: Irapuá, uma aldeia na beira da estrada BR-290, e Tekoá Porã, aldeia demarcada localizada no município de Salto do Jacuí.

Logo na chegada à Tekoá Porã, me aproximei a uma família extensa que tinha ido morar lá após um período conturbado passado na região de Misiones, na Argentina - na aldeia Tekoá Tamanduá. Foi em Tamanduá que Kanuto se transformou em onça. De acordo com meus amigos e interlocutores, todos os Mbyá podem tornar-se um ojepotá e isso pode

\footnotetext{
${ }^{4}$ Utilizarei aqui o termo "branco" para falar sobre a alteridade "não indígena", pois me parece ser assim a forma que os Mbyá-Guarani acham melhor para marcar essa diferença. Mais adiante, também usarei o termo êmico juruá para designar os não indígenas.

5 Mesmo que esse entendimento venha a se transformar dialeticamente entre convenção e invenção (WAGNER, 2010).

${ }^{6}$ Para ver mais sobre o jeguatá, sugiro Souza Pradella (2009a e 2009b).
} 
ser um processo demorado - pode-se passar meses sem ninguém perceber a transformação. Se a pessoa mbyá começa a desenvolver desejos muito acentuados com relação à carne, principalmente se ela estiver quase crua, ou se pratica a caça exageradamente, ou, ainda, se começa a gostar de ficar sozinha no mato durante muito tempo - pode estar se desenvolvendo uma transformação - ojepotá.

Um dos aspectos mais importantes que ativam a transformação em ojepotá é o descontrole da libido (PISSOLATO, 2006). A relação do ojepotá com o sexo é bastante ressaltada nas aldeias. Simples caminhadas pelo mato podem ser trágicas na perspectiva mbyá, já que são nesses momentos afastados dos parentes próximos que podem aparecer na mata algumas miragens sensuais, seduzindo principalmente os mais jovens a ficarem no mato por mais alguns minutos, horas e dias.

Segundo Maria Paula Prates (2009), o risco de "ojepotar-se" é maior para as mulheres em comparação aos homens, pois elas estariam mais suscetíveis a essas transformações por causa da menstruação - o sangue é algo que as deixam sensíveis aos outros seres do cosmos (PRATES, 2009). Mariana Soares (2012), além de relatar o caso de Kanuto, narra outro ocorrido em São Paulo, onde um homem teria sido enterrado sem ninguém notar nada, mas a partir do sonho de um karaí (xamã) a aldeia resolve desenterrá-lo, e assim identificam a transformação: o homem estava sem pelos no corpo e com os braços compridos - "tornando-se uma espécie de cobra, minhoca ou animal aquático" (SOARES, 2012, p. 95).

No caso específico da história de Kanuto, a fagulha inicial que desencadeia sua transformação em onça é a composição da solitude na mata com o desejo pelo sangue das carnes cruas. O contato com o sangue junto com o afastamento dos parentes acaba criando outro espectro de socialidade para Kanuto. Tempass (2010) ressalta que as carnes caçadas passam determinados atributos interessantes quando consumidas pelos Mbyá. Por exemplo, quando os Mbyá consomem tatu, adquirem sua força e se protegem de ataques inimigos (em referência à carapaça do tatu); quando consomem lebre, ficam mais ágeis; e se comem alguma paca fortalecem seus dentes. De acordo com o mesmo autor, "é pela alimentação que se tem maior eficácia na transmissão dos atributos simbólicos" (TEMPASS, 2010, p. 173). Contudo, ao mesmo tempo em que 
a caça é valorizada, determinados atributos dela são perigosos, como é o caso do tupixuá.

Imagem 1: Kanuto.

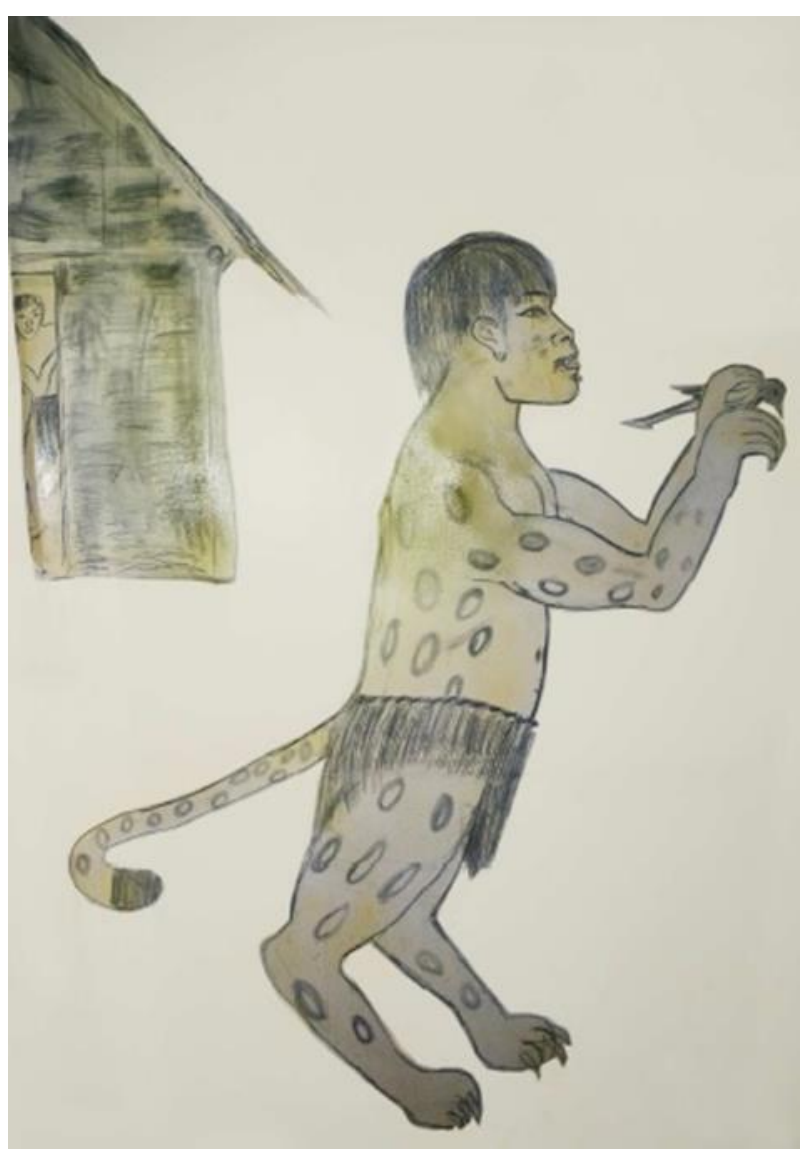

Fonte: Soares (2012, p. 95).

O tupixuá é descrito como um espírito que habita os animais e que pode fazer adoecer os Mbyá caso consumam a carne crua. Somente o cozimento dos alimentos afasta o risco do tupixuá, pois seria justamente essa característica da carne crua um dos agentes da transformação (TEMPASS, 2010 , p. 174). A interdição do cru está ligada com a importância dada ao sangue como agente de contágio, sendo o principal operador de transformações. Conforme já relatado, o sangue da primeira menstruação é diretamente relacionado com o risco de ojepotá (PRATES,

\footnotetext{
${ }^{7}$ Sobre o tupixuá, ver mais em Tempass (2010), autor que ressalta sua relação com o jaguar: “... a existência de 'espíritos malignos' que 'habitam' os animais. Estes, apesar de serem vários, são corriqueiramente designados pelos Mbyá-Guarani simplesmente como tupixиa (ou pixиa), que é o espírito da carne crua, ou o espírito do jaguar ou ainda o espírito dos animais. (...) O tupixua é um agente para a transposição do domínio da sociedade para o da natureza" (TEMPASS, 2010, p. 157).
} 
2009) devido a ser um dos mais fortes motores de contágio de perspectivas - mais adiante veremos como o sangue também é chave para entendermos a relação entre os Guarani e os juruá (os brancos).

A partir dessas noções importantes, começamos a compreender onde residem os riscos desencadeadores do processo de ojepotá. Vale ressaltar sua relação com a libido, que nas lógicas mbyá parece assemelhar-se ao desejo pelo sangue da carne crua - remetendo-nos, talvez, à relação de presa/predador implicada nas relações sexuais. Contudo, há outros processos que ocorrem concomitantemente a esse que culminam na metamorfose, dentre eles é imprescindível ressaltar o gradual desprendimento da ñe'e e a imposição de outra perspectiva presente no mundo sobre os corpos mbyá 8 . Passemos a essas duas faces do processo transformacional: o abandono da socialidade humana-mbyá e a imposição coercitiva e dolorosa de outrem sobre um mbyá.

Segundo os Mbyá, a ñe'e seria o que mais se aproximaria de "nosso" conceito de alma. Ela seria o condutor da humanidade lançada pelos deuses ainda no ventre das mães ${ }^{9}$, mas somente identificada no momento do nhemongaraí0 - importante ritual realizado na opy (casa de reza) na época após a colheita do milho - no tempo de Ará Pyau (tempo primeiro, original), mais facilmente traduzido como primavera/verão, mas que se relaciona a diversos aspectos cosmológicos primordiais da Terra ( $y v y$ yma $)^{11}$.

A partir da chegada da ñe'e, diversos são os cuidados que se deve tomar para que a alma não se desprenda do corpo e para que a pessoa mbyá não acabe se tornando outro (espírito, onça, planta, etc.). Esse cuidado envolve uma série de restrições e prescrições por parte da mãe e do pai, assim como dos parentes que estiverem mais próximos. Até os anos iniciais da criança, a ñe'e está sensivelmente assentada no corpo: a

\footnotetext{
${ }^{8}$ Para mais sobre a noção de imposição, ver em Souza Pradella (2009a) e Heurich (2011).

9 "O nhe'e [alma] de uma criança é trazido do mundo divino, através do apyka [banco ritual], para se assentar no ventre da mãe" (ASSIS, 2006, p. 87 apud SOARES, 2012, p. 67).

${ }^{10}$ São inúmeras as digressões sobre o nhemongaraí; para a primeira descrita na etnologia, ver Nimuendaju (1987). Nesse ritual ocorre o "batismo" de todas as sementes e o descobrimento pelos karaí (xamãs) dos nomes das crianças, ou, mais especificamente, do lugar de onde as ñe'e vieram. Se as ñe'e vieram de Tupã Ru Eté (divindade das chuvas e raios), são alguns nomes que se pode dar aos pequenos guarani, como por exemplo o nome de Verá aos meninos e de Pará às meninas; se vieram de Ñamandu Ru Eté (divindade do Sol) são outros, como, por exemplo, Kuaray para meninos e Jachuka para meninas. Para uma relação completa dos nomes de acordo com as divindades que os enviam, ver Soares (2012).

${ }^{11}$ Cf. Cadogan (1992).
} 
qualquer distúrbio pode-se perdê-la.

Um caso que acompanhei e que ilustra o desprendimento trágico da ñe'e ocorreu quando uma criança veio a falecer devido a um susto tomado na beira da estrada BR-116, rodovia que corta o estado do Rio Grande do Sul. Após sofrer um susto por ter sido quase atropelada por um caminhão que trafegava em alta velocidade na rodovia no momento em que brincava com outras crianças, a vítima não tardou muitos dias para ficar enferma e falecer no hospital. Segundo os Mbyá, foi uma combinação de fatores que causaram a morte da menina. As consequências decorrentes do susto poderiam ter sido revertidas caso não fosse a falta de terra para plantar avaxi (milho), a falta de mato para buscar determinados remédios, e o posterior isolamento da criança em um hospital - esses fatores conjugados fizeram a ñe'e abandonar o corpo. As condições de falta de acesso a esses elementos de fabricação e manutenção do corpo (citadas como a relação com o mato e a alimentação à base de avaxi) não possibilitaram que os karaí (xamã) conseguissem manter a ñe'e nesse plano e no corpo da criança, ainda mais tendo que "trabalhar" dentro de um hospital. São incontáveis casos como esse dentro do contexto atual de territórios minúsculos que as frentes civilizatórias impuseram aos Mbyá.

As correspondências entre as noções mbyá sobre o corpo são supreendentemente próximas às wari' relatadas por Vilaça (2002 e 2005). De fato, o corpo mbyá precisa ser submetido a "processos intencionais, periódicos, de fabricação" (VIVEIROS DE CASTRO, 1979, p. 31), e o fato dos parentes serem humanos não determina a humanidade da criança (VILAÇA, 2002, p. 349). As fronteiras dos corpos das crianças são permeáveis, gerando instabilidade em sua forma, já que a partir de qualquer distúrbio podem transformar-se em outro. A ñe'e é recebida enquanto a visita de uma certa divindade nos corpos, e para mantê-la neste plano terrestre e no corpo mbyá, ela precisa ser gradualmente trabalhada a partir de ações específicas, incluindo comidas e práticas especificamente mbyá.

Como no caso dos Wari', a ñe'e guarani não parece dar ao corpo somente "sentimentos, pensamentos e consciência, mas instabilidade" (VILAÇA, 2005, p. 452 - minha tradução). Essa instabilidade dos corpos faz as $\tilde{n}$ 'e desprenderem-se, conferindo, por sua vez, uma desfiguração 
corporal. Dito de outra maneira, se o cultivo e a manutenção da ñe'e são boas maneiras para se manter guarani, seu desprendimento pode acabar causando uma transformação corporal e de ponto de vista - a morte da perspectiva guarani. Isso porque as diferentes perspectivas não podem ser somadas, algo que configuraria uma espécie de hibridez consumptiva - uma miscigenação/mestiçagem (KELLY, 2014). Dessa forma, a imposição de uma perspectiva aparece sempre com um valor dominante, implicando uma hierarquia sempre definida a posteriori (VILAÇA, 2005, p. 459).

Dentro deste contexto de formas mal definidas e instáveis, os -já aparecem como responsáveis pela imposição de ponto de vista sobre os corpos (HEURICH, 2011). Essa figura povoa o cosmos guarani e possui a capacidade de "impor" sua perspectiva sobre outros seres, fazendo-os perder sua perspectiva original. Esse seria o caso dos ojepotá, que cederiam sua perspectiva mbyá para outros -já - nesse caso específico de Kanuto, ao xivyjá (guardião-espírito da onça).

A figura -já é muito importante para entendermos o processo do desprendimento da ñe'e e, consequentemente, do ojepotá. "Dono" parece ser a principal tradução utilizada pelos Mbyá para essa figura. Seriam entidades "donas" de determinadas espécies (xivyjá - das onças), plantas (yvyradjá - das árvores), sentimentos (takateydja - dos ciúmes), e até mesmo geografias (itajá - das pedras) ${ }^{12}$. Segundo alguns autores (SOUZA PRADELLA, 2009a; SOARES, 2012), essas figuras seriam espíritos que cuidariam de seus "representantes", que habitam os mesmos planos terrestres dos Guarani.

Um local propício onde vivem um dos -já mais presentes no mundo mbyá são os rios. Por normalmente estarem perto de pedras, os itajá (donos das pedras) podem ser facilmente incomodados por barulhos provocados pelas pessoas que vão pescar ou simplesmente se banhar. Com sua aldeia em um plano cósmico próximo ao dos Mbyá, os itajá não gostam de ser perturbados, e cuidam se alguém pesca demasiadamente seus peixes ${ }^{13}$.

\footnotetext{
12 Termos coletados em campo, e também em Heurich (2011, p. 41).

${ }^{13}$ Já tive algumas experiências ruins com relação aos itajá, deixando-me doente e quase levando-me rio abaixo em determinada ocasião (digna de muitas risadas e também de preocupações). Fui obrigado a buscar tratamento com os karaí para que tirassem as pedrinhas alojadas em minha cabeça. Soares (2012, p. 227) relata a recuperação de Karaí Tataendy quando este foi atacado por itajá. O motivo do ataque seria porque
} 
Os -já estão por toda a parte, zelam para que seus "representantes" em planos terrestres não sofram distúrbios que podem ser causados por outros seres. Além disso, são responsáveis pela maior parte das precauções e preocupações dos Mbyá - desde restrições alimentares e práticas rituais, povoando os perigos da menarca e da couvade, eles se impõem enquanto perigo ao mundo dos Mbyá (HEURICH, 2011). Heurich (2011, p. 40) sugere a tradução como "espíritos-dono" - e ressalta a equivalência relacional entre -já e $\tilde{n} e^{\prime} e^{14}$. Segundo seus interlocutores, os Mbyá seriam aqueles que possuem a ñe'e, enquanto Outros (inclusive os brancos) possuiriam seus equivalentes -já. De acordo com alguns mbyá, os juruá também possuem ñe'e, e a diferença seria que os Mbyá, além de possuírem uma ñe'e, também teriam mais duas "almas/espíritos": a ñe'e mbyté e o ãy.

Imagem 2: Lugar propício para o itajá no Salto do Jacuí.

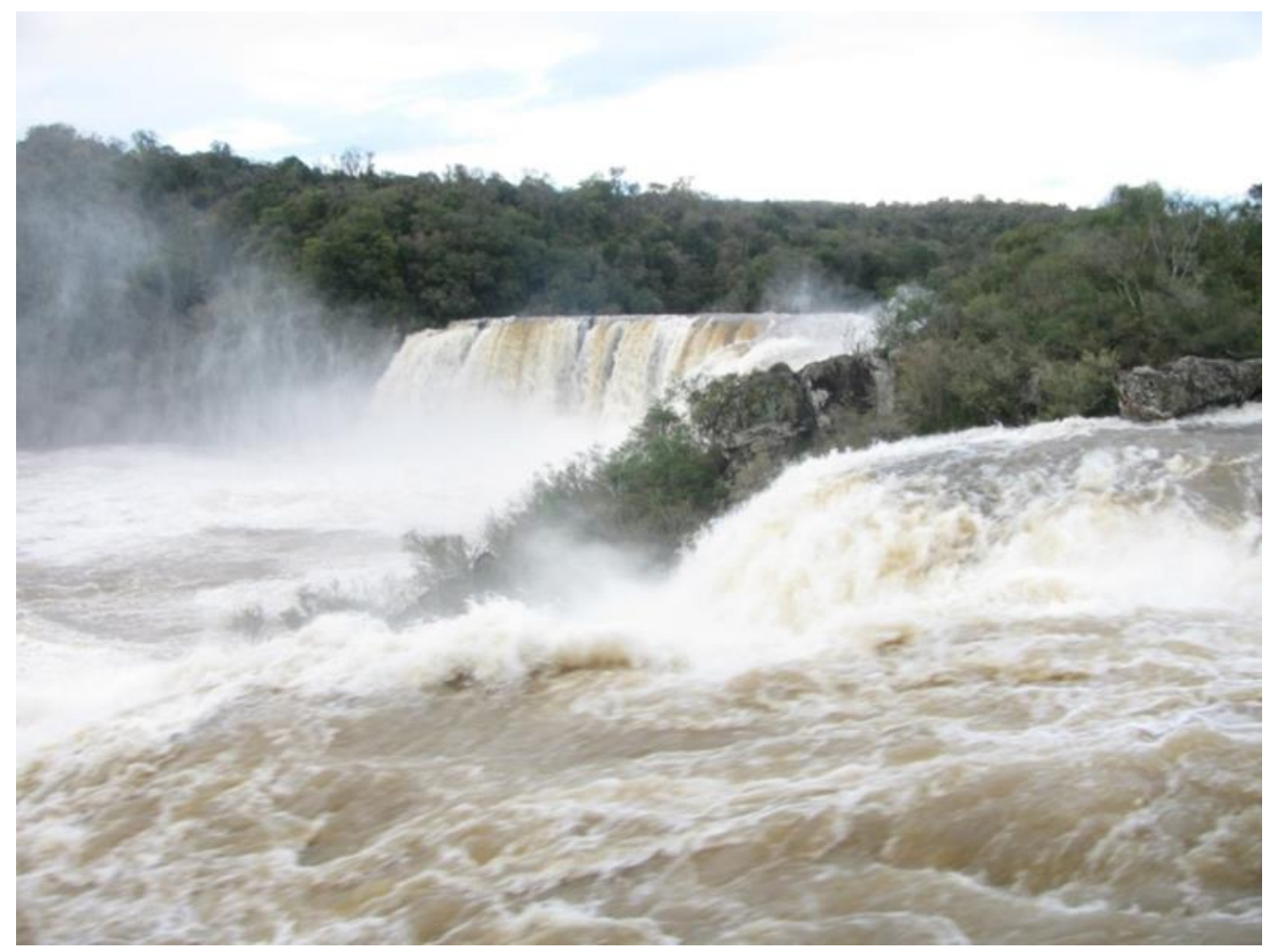

Fonte: Fotografia do autor.

pescava exageradamente sem cuidar com o barulho e desorganização que fazia junto às pedras do rio. Dessa forma, foi curado pelo karaí Iapuá, que retirou pedrinhas de seu joelho.

${ }^{14}$ Heurich (2011) pergunta se os animais tem ñe'e, e escuta que não, que possuem seus já - assim como os não-indígenas. 
O importante a se ressaltar é que para o ojepotá se estabelecer corporalmente, é necessário que a partir do desprendimento da ñe'e de um humano guarani, venha se impor um -já. Ou seja, os já teriam a capacidade de impor sua perspectiva sob as ñe'e mbyá - uma imposição que poderíamos caracterizar como coercitiva e que motivaria a transformação.

Dessa forma, tudo aquilo que tem seu respectivo -já se apresenta como uma possível agência sob as formas mbya. Segundo me contaram, até mesmo a preguiça pode se impor sobre um corpo guarani, fazendo com que a pessoa não consiga se levantar por estar tomada pelo ateyja. Sem a imposição de um -já não há nenhum espírito que se desdobre em corpo, fazendo do desprendimento da ñe'e uma perda total da forma (desdobramento do corpo em somente espírito15) - como o caso da criança que faleceu devido ao susto tomado na beira da estrada.

Ao que me parece, as teorizações mbyá sobre a possibilidade de transformar-se corporalmente corroboram com certos conceitos amplamente identificados entre os ameríndios das Terras Baixas SulAmericanas. O corpo indígena não pode ser pensado enquanto Uno, sustentando papéis sociais, ou como palco de performances representacionais. Aqui, o corpo é a matriz dos símbolos, é o locus onde será experienciada uma perspectiva, e as relações sociais específicas. Ele "é a um só tempo individual e coletivo, social e natural" (SEEGER, DAMATTA e VIVEIROS DE CASTRO, 1979). O corpo forma a pessoa ameríndia: ao fabricarem seus corpos, ou corpos outros, os ameríndios transformam sua pessoa, assim como sua organização e posição no cosmos.

As bem conhecidas noções discutidas por Viveiros de Castro (2002) sobre o perspectivismo ameríndio ajudam a perceber como a onça não se configura enquanto um animal isento de reflexividade. Ao contrário, vemos como a onça não só possui uma perspectiva como também é capaz de capturar humanos e fazê-los viver enquanto onças. Ao transformarse em onça, Kanuto era um grande risco para os Mbyá-Guarani de sua

\footnotetext{
${ }^{15}$ Vilaça (2002) defende que não podemos entender essa relação entre corpo e espírito como concomitantes, mas como figura e fundo, já que a alma só existiria na ausência de corpo. Pedro Pitarch (comunicação pessoal) defende a noção de dobra para ilustrar essa relação entre alma e corpo.
} 
aldeia, pois seus antigos parentes com os quais ainda mantinha certa proximidade eram agora vistos como presa - da afinidade com as onças passaria a compartilhar consanguinidade.

Heurich (2011) defende que a noção de -jáajudaria-nos a entender essa agência comum a todos os seres no caso específico dos Mbyá, ou seja, configuraria o polo "cultura" comum no jogo relacional entre humanos e não humanos. Isso se deve ao fato de a maioria dos seres e entes possuírem seu próprio -já, uma entidade reflexiva que protege suas "sociedades", um espírito-dono e agente comunicador inter-espécies. No caso de Kanuto, o xivyjá (espírito-dono das onças) impôs sua perspectiva sob o corpo mbya-guarani através de diferentes técnicas. Não conseguimos saber se Kanuto viu primeiro uma miragem sensual na mata quando caçava, ou se simplesmente passou a se alimentar de carne crua - é bem provável que sim, já que os relatos sempre insistem na miragem sensual como principal técnica utilizada pelos espíritos para capturar pessoas. $O$ predador se finge de presa enquanto uma sedutora miragem com o objetivo de que pela aliança consiga capturar um futuro parente.

Nesse contexto instável, o parentesco surge como método relativamente eficaz para assegurar a forma. Como dito acima, se é pela alimentação que se tem maior eficácia na transmissão dos atributos simbólicos, passa também pela comida e pela comensalidade a manutenção de determinada forma humana. Contudo, o parentesco deve ser entendido em seu sentido mais amplo, em que a relação com a alteridade é impossível de ser ignorada:

Defendo aqui que o exterior é parte constitutiva das relações de parentesco na Amazônia como uma consequência do fato de que essas relações são construídas a partir da alteridade enquanto um ponto de partida. A produção de parentes está relacionada ao universo supra-local não simplesmente por causa da necessidade de capturar identidades e potências do exterior, como numerosas etnografias amazônicas testemunham, mas também porque a humanidade é concebida enquanto uma posição, essencialmente transitória, continuamente produzida a partir de um vasto universo de subjetividades que incluem os animais (VILAÇA, 2002, p. 349 - minha tradução).

Assim, o parentesco é construído através de práticas cotidianas que 
não ignoram as alteridades. Um caso exemplar dessa construção de afins que nos ajuda a passar à segunda parte deste artigo foi relatado por José Kelly (201 1), quando entre os Yanomami escutou a história de um menino que foi morar na cidade e, depois de passar os primeiros dias chorando por estar longe de seus parentes yanomami, começa a chamar os brancos que o haviam levado com os termos de parentesco (pai e mãe). Quando ele é levado de volta para a aldeia, alguns dias depois, já não consegue reconhecer mais seus pais yanomami, nem mesmo a língua falada (KELLY, 2011 , p. 70). O compartilhamento de substâncias (fluidos, alimentos, etc.) gera um processo de mudança de ponto de vista conjuntamente com uma transformação do espectro da sociabilidade - os parentes passam a ser outros.

Entre os Mbyá-Gguarani, os -já são peças chaves para entendermos esses processos de consubstancialização. Esse ser (dono-mestre) que habita um espaço intermediário entre a terra e o céu é caracterizado como dono de grupos específicos - das onças às pedras -, possuindo uma atitude para com aqueles que desrespeitam suas propriedades digna de um senhor de terras que sem pestanejar usa de métodos coercitivos para impedir a pilhagem de suas propriedades. Além disso, os jáainda buscam aumentar suas sociedades impondo-se sobre corpos de outros grupos, humanos mbyá ou de outra natureza. Se a propriedade não é sobre o território, a negociação política das organizações sociais passa pela propriedade do corpo. Nada melhor, portanto, que um xamã apareça como diplomata em diálogo com as divindades para essa disputa. O poder coercitivo é, dessa forma, muito mais difundido entre diferentes humanidades (inter-espécies) do que somente entre os humanos-mbyá. Sua negociação envolve a fabricação e manutenção dos corpos através do parentesco e das relações diplomáticas desenvolvidas pelos karaí(xamãs) - corroborando a ideia de que o perspectivismo é o correlato cosmológico da sociedade contra o Estado (VIVEIROS DE CASTRO, 2011 e 2013).

Discutidos esses conceitos etnológicos mbyá-guarani e sua relação com a antropologia mais ampla das Terras Baixas Sul-Americanas, onde mantém-se a noção de maleabilidade da forma e resiliência de uma agência-reflexiva, podemos tentar pensar o lugar simbólico ocupado pelo não indígena a partir desse arcabouço teórico. Qual o lugar dos brancos nas mitológicas guarani? Será que podem se transformar em brancos? 
Qual o lugar, as potencialidades e o perigo dos brancos nesse jogo relacional?

\section{Os juruá}

Foi aproximadamente na década de 1990 que Jose, um dos mais importantes xondaro (corruptela da palavra "soldado", designando guerreiro indígena - relativa à noção de yvyra'i já: dono dos bastões-insígnia) da Argentina da época, decidiu abandonar sua família mbyá e partir rumo à cidade. Jose, filho de uma importante liderança política e sacerdotal, era extremamente respeitado, chegando a organizar expedições guerreiras com mais de 100 homens contra aldeias inimigas. Em determinado momento de sua vida, entretanto, passou a gostar demasiadamente do tekó axy, um modo-de-ser e um arcabouço teórico que se opõe ao tekó porã aquele que busca a leveza do espírito a partir de uma relação de escuta às divindades. Os conhecimentos do tekó axy são promovidos por uma série de seres "malditos" do cosmos, sendo ainda um "mundo" evocado a partir do uso excessivo do álcool.

Como o álcool está melhor localizado nas cidades do que nas aldeias, alguém que bebe muito acaba entrando em relação com os juruá mais frequentemente. Enquanto fornecedores de álcool e de conceitos mundanos, os juruá passam a povoar o mundo dos caú (bêbados). Foi nesse contexto que Jose acabou sendo capturado pelas seduções de uma xenhorá (branca), que, enfeitiçando-o, passou a maldizer sua família. Jose, mudando-se para a cidade, passou a ser um risco a seus familiares, pois a serviço da xenhorá organizava uma série de ataques xamânicos e violentos a seus filhos e ex-mulher. Depois de algum tempo tentando se proteger de Jose e de sua nova companheira, alguns de seus filhos e sua ex-mulher decidiram mudar-se para longe de Misiones (Trecho de diário de campo).

$\mathrm{Na}$ seção anterior vimos como a libido e o sangue servem como idiomas da transformação de ponto de vista, e ainda como a transformação é causada quando há uma imposição de uma perspectiva sobre outra. A seguir veremos como esses mesmos temas são lançados para se pensar a relação com os juruá.

Dentro de minhas experiências em campo, os não indígenas foram 
descritos a partir de uma certa gama de termos e definições. Quando no singular, os Guarani normalmente designam o branco masculino como juruá e a não indígena como xenhorá, mas existem outros termos que demarcam outras diferenças fenotípicas, como o negro: cambá. Contudo, em termos generalizantes, é comum sermos todos coletivizados como não indígenas a partir da expressão juruá kuery. Com relação ao termo juruá, há duas definições utilizadas pelos Guarani: pode tanto significar "boca peluda", com referência à barba dos antigos (e atuais) colonizadores, assim como também se refere a uma característica muito comum àqueles que se relacionam com os Guarani: "palavras ao vento" referindo-se à falta de confiança nas palavras dos não indígenas, palavras enganadoras. Essa noção de que não se pode confiar nas palavras nem nas promessas dos juruá encontra-se amplamente difundida nas aldeias.

Apesar de juruá ser o termo mais usado, existem outros termos que servem para designar o não indígena, dependendo do contexto em que se fala e também das experiências de relação com os juruá que o narrador tenha cultivado. Um desses termos seria utilizado pelos mais velhos, os xeramoi e xejaryi, conhecidos e retratados pela preferência no uso de metáforas ao se comunicarem; eles muitas vezes se referem aos brancos como yvypó kuery (yvy - terra; pó - mão; kuery - coletivizador). Este termo, que também é uma expressão, pode ser traduzido como "o grupo que se adona da terra", ou a "mão dona da terra", referindo-se a uma ideia de apropriação ou propriedade da terra que os coletivos não indígenas parecem praticar. Há ainda termos mais difíceis de serem escutados, como o que fala sobre a relação entre os não indígenas e os gafanhotos. Talvez pela sua fama de predador das plantações, pode-se chamar aos brancos como karungá kuery (karungá - gafanhoto), termo que ainda mantém certa correspondência (desconhecida por mim) com o arco-íris: karungá di'y $y^{16}$.

Sem deter-me em caracterizar os diversos planos celestes e terrestres existentes na cosmografia mbyá, o importante é simplesmente ressaltar a existência de "uma miríade de populações celestes" (PIERRI, 2013, p. 31) na medida em que a relação com os juruá não se restringe ao plano terrestre somente, tendo origens diversas e existências

\footnotetext{
${ }^{16}$ Pode existir uma relação do arco-íris com as doenças, conforme ocorre com os Yanomami (LIZOT apud KELLY, 2011, p. 58).
} 
concomitantes em planos mais acima da terra. A existência de diversos planos cósmicos na cosmografia mbyá-guarani já foi referenciada por outros autores (SOUZA PRADELLA, 2009a; HEURICH, 2011 ; PIERRI, 2013 ).

De acordo com os Mbyá-Guarani as características enganadoras e mesquinhas dos juruá podem ter como causa a maneira pela qual os brancos surgiram no mundo. Há duas histórias mais conhecidas que contam um pouco sobre essa origem. Uma delas conta que os brancos seriam descendentes de uma lagarta (mbi'l) de proporções gigantescas localizada em meio ao Oceano Atlântico, dona de uma ilha contornada por águas pegajosas que nenhum barco atual consegue enxergar, justamente por fazer parte de outro plano cósmico de difícil acesso aos próprios brancos. A lagarta é conhecida pela capacidade de atacar plantações de milho.

Outra história difundida pelas aldeias é a descendência direta dos juruá de Tupã, divindade das águas e das chuvas. Assim como as divindades guarani que vivem em planos mais elevados no cosmos, os juruá também teriam sua divindade vivendo em uma casa mais acima dos planos terrestres, para onde são enviados os espíritos-almas não indígenas. A história conta o seguinte: Primordialmente, Tupã teria enviado um filho para o plano terrestre na tentativa de mostrar aos juruá o quão longe do caminho divino estavam com seu modo de vida destrutivo, pois os juruá não paravam de sobrepor aquilo que havia sido designado a eles (campos, vacas, porcos, etc.) sobre os elementos designados aos Guarani (matas, milhos, caça, cachimbo, etc.). Contudo, mesmo após o filho de Tupã ter sido enviado, os juruá não perceberam que se tratava de uma divindade e por isso o assassinaram na cruz - esse filho seria Tupãra'y, traduzido como o próprio Jesus.

Durante a caminhada de Tupãra'y na terra, ele vai criando vários seres e elementos que no futuro serão imprescindíveis aos brancos, tratando-se de uma correspondência muito aproximada da história dos "gêmeos" mbyá (Kuaray e Jaxy, que vão criando tudo que existe no mundo, principalmente as coisas consideradas importantes aos Mbyá). No caso do mundo juruá, foi Tupãra'y que em seu caminho vai criando tudo aquilo que constitui como o campo relacional próximo dos brancos aos olhos mbyá: os campos, os patos, as vacas, os porcos e, mais tarde, a tecnologia - campo este totalmente oposto e diverso ao dos Guarani 
(PIERRI, 2013).

Imagem 3: A soja e o pórtico do município com árvores de concreto, já que seu nome é Derrubadas.

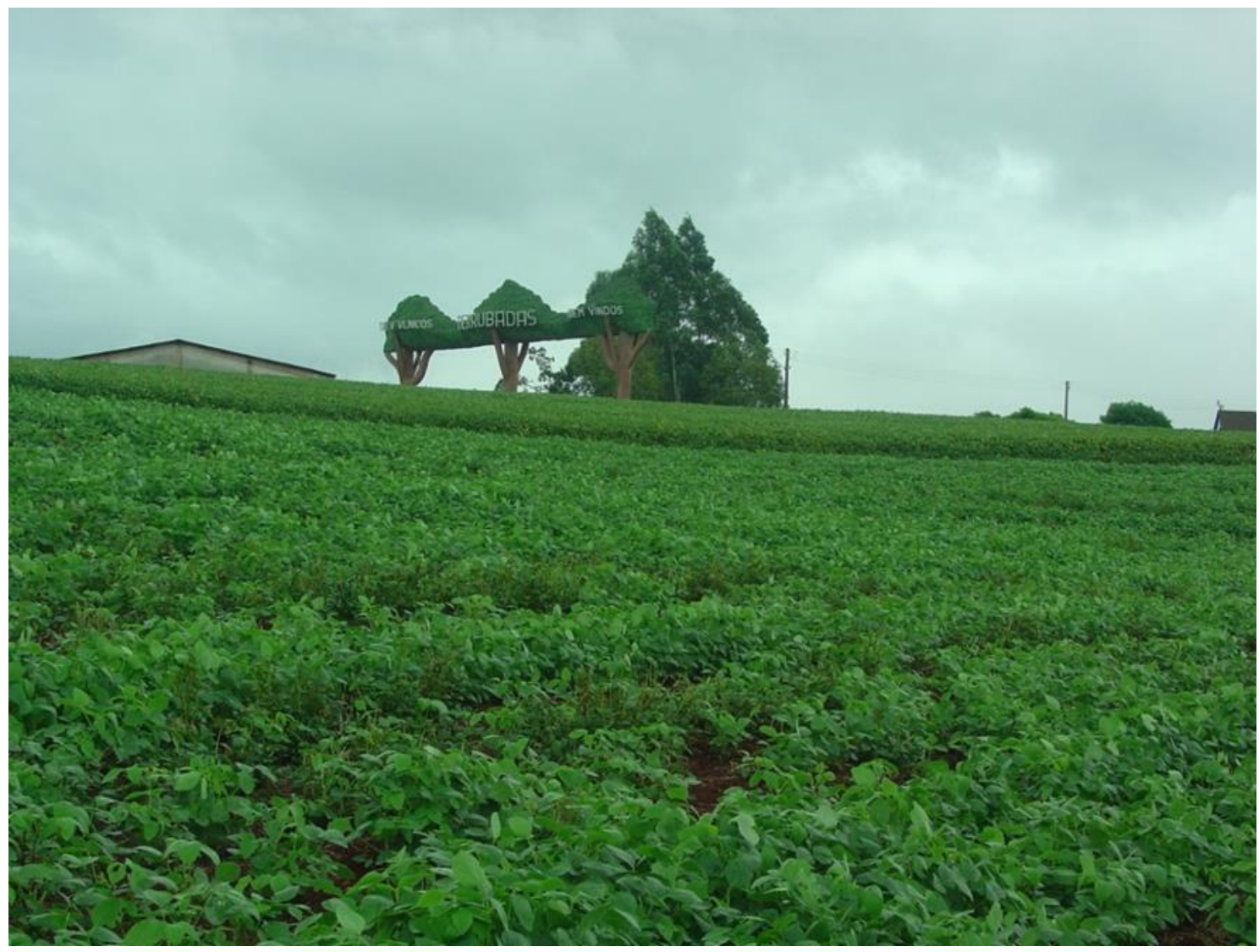

Fonte: Souza et al. (2010).

Essa origem em Tupãra'y também explica os costumes desenvolvimentistas e destrutivos dos brancos, pois enquanto os Guarani seguem os ensinamentos de Kuaray, os juruá não só mataram sua própria divindade na cruz, como não escutaram suas palavras (PIERRI, 2013) algo imprescindível para deixarem de se impor sobre o mundo mbyá. Ao assassinarem Tupãra'y, assassinaram também a reflexividade de suas próprias ações e com isso suas lógicas desenvolvimentistas seguem operando - a comunicação com as divindades foi perdida -, fazendo os brancos seguirem desenvolvendo sua característica colonialista com a qual não pararam de impor os campos às matas.

Essa característica de sobreposição dos campos sobre as matas, nos faz remeter à ideia da imposição dos -já sobre os corpos mbyá que 
discutimos na primeira parte deste artigo. É neste momento que se percebe como a relação com os juruá deve reservar os mesmos cuidados da que se tem com as onças, por exemplo, pois os juruá também podem causar uma mudança de ponto de vista. Como vimos anteriormente, a imposição do xivyjá (dono das onças) sobre Kanuto tinha como gatilho o contato com o sangue cru e o desejo libidinoso. Com relação ao sangue, os Mbyá relatam que o sangue dos não indígenas é mais forte e pesado se comparado ao dos Guarani, que seria leve e fino. Dessa forma, ao trocarem fluidos (sexuais, principalmente ${ }^{17}$ ) há uma tendência de que o sangue/fluido dos não indígenas venha a se impor sobre o corpo mbyá, causando doença - algo que está diretamente relacionado com a troca de ponto e vista, ou de forma corporal:

\begin{abstract}
Por exemplo, uma doença - muitas vezes explicada como um ataque à alma por uma espécie animal particular - é sempre vista e tratada como um processo de transformação corporal (...). O que parece claro aqui é que a doença, tanto de um recém-nascido quanto de um adulto, produz um desses momentos em que o corpo humano pode ser refeito ou pode assumir outra forma (VILAÇA, 2002, p. 361 - minha tradução).
\end{abstract}

Aqui também o desejo sexual é central para entendermos o risco de contágio de perspectiva e a trágica consequência da perda de parentes para a alteridade. Ao acreditar nas palavras falsas (palavras ao vento, como muitos chamam os juruá), ou deixar-se seduzir pelas miragens sensuais que aparecem nas matas ou nas cidades, os Mbyá podem cair em um desejo descontrolado pelas / os xenhorá/juruá, tal como parece ter ocorrido com Jose. E mais, depois da transformação ter ocorrido, Jose passa a ser um risco para seus antigos familiares, na medida em que ainda conserva traços de afeto com eles - exatamente como ocorrera com Kanuto.

Outra evidência de que há uma transformação de ponto de vista reside no fato de que quando um mbyá relaciona-se sexualmente com um/a não indígena ele perde a comunicação com as divindades mbyá,

\footnotetext{
${ }^{17}$ Ouve-se muito nas aldeias sobre ser imprescindível o uso da camisinha em relações sexuais entre os/as Guarani com os/as brancos/as. Os motivos dessa necessidade, contudo, não estão diretamente relacionadas às doenças sexualmente transmissíveis (apesar da contração de doenças ser o foco em questão), mas sim com o fato dos fluidos juruá poderem sobrepor-se aos Guarani.
} 
pois passa a ouvir outras. Aqui o cachimbo também nos ajuda a perceber as nuances dessas relações. Conforme vimos anteriormente, o cachimbo foi um dos "objetos" destinados aos Mbyá desde sua origem e ainda hoje serve para estabelecer uma comunicação com as divindades - é como um telefone celular, como alguns amigos mbyá me ressaltaram. É justamente essa comunicação, algo que remete à origem dos Mbyá, que se perde quando se entra em consanguinidade com os não indígenas. Determinados xamãs mais estritos não tratam os Mbyá que tenham mantido relações sexuais com juruá por medo de também perderem a comunicação através de contágio.

As histórias de Kanuto e Jose foram duas das primeiras que escutei em campo. De certa maneira, elas tratavam de me ilustrar as preocupações mbyá com as relações com os não indígenas motivadas pela minha presença - contando a história de certos eventos importantes que levavam aqueles narradores a estarem onde estavam (GOW, 2001).

Se estou equivocando de maneira correta (VIVEIROS DE CASTRO, 2004), me parece que os perigos da relação com as alteridades de outras naturezas (onças) é correlato àqueles da relação com os juruá:
Meu ponto é que, se reconhecermos o fato de que a humanidade não é limitada aos Wari', estaremos em uma posição melhor para entender que a produção de parentes consubstanciais pela fabricação de corpos idênticos ativa, não somente o universo restrito ao grupo local ou ao grupo étnico/tribal, mas também um universo mais amplo de subjetividades a partir do qual os diferentes grupos são construídos (VILAÇA, 2002, p. 355 - minha tradução).

Apesar das alteridades aparecerem como interessantes por suas potências, as relações não podem ser promovidas sem um grande cuidado de proximidade excessiva. Na mata, as miragens promovidas pelos -já aparecem com discursos falsos e promessas enganadoras que sequestram os Mbyá mais desejosos por suas "carnes". Nas cidades, os juruá, com suas "palavras ao vento" ainda mais enganadoras, oferecem um mundo outro que afasta das aldeias os Guarani enfeitiçados por suas tecnologias e por seus corpos sedutores. A carne crua de um é a carne nua de outro. 


\section{Desdobramentos finais}

Fausto (2008) desenvolve longo argumento sobre a centralidade das relações de dono-maestria entre os ameríndios das Terras Baixas SulAmericanas. Tal modelo de relação também parece ser importante quando passamos dos donos aos brancos, na medida em que ambos praticam as mesmas técnicas de imposição de perspectiva sobre os Mbyá. As miragens dos -já e dos juruá simulam uma condição de presa, quando na verdade são predadores colocando em risco principalmente os mais jovens, ansiosos por conhecerem as alteridades. Assim como o jovem que ao enxergar a miragem sexualizada se engana sobre sua natureza comum, o mesmo jovem que enxerga o branco também não deveria confiar nas coisas que fala, nem acreditar nas que escreve: as seduções das miragens, a troca substancial e carnal (sexo), podem enfraquecer os corpos biologicamente frágeis dos Mbyá, fazendo-os doentes e levandoos para outro ponto de vista.

Do desejo por carne (crua ou nua) à imposição coercitiva de outrem sobre os corpos guarani, parece haver um receio de não saber experimentar o devir sem uma boa medida de distância (LÉVI-STRAUSS, 1986). Vimos como há um certo padrão de relação, informado pela relação entre os donos e os Mbyá, que se universaliza para as relações em geral, ou seja, a relação dono-maestria "opera em diferentes escalas, desde a microconstituição da pessoa até a macroconstituição do cosmos" (FAUSTO, 2008, p. 348). Contudo, me parece que, antes de informar a existência de uma centralização do poder, salienta a difusão de um poder coercitivo espalhado através do cosmos - desdobrando a guerra contra Estado (CLASTRES, 2003) em um verdadeiro modo de insubmissão cosmológica, em que a mesa de negociação passa pela mesa do jantar, onde se produz e mantém os parentes, e pelos "diplomatas" karaí, que negociam com outros a manutenção da saúde de seus grupos.

A partir dos relatos acima, portanto, parece-me que tanto na origem quanto nas atuais relações praticadas com os brancos há um sistema de boa distância em que a relação é mediada pelo interesse (mútuo), mas sempre sob o risco de uma junção consumptiva tal qual a mestiçagem parece advogar (KELLY, 2014) e a qual os Guarani também 
parecem se opor. Aqui, o que está em jogo é a purificação entre índios e brancos perpassada por aquela entre "humanos" e "não humanos" (KELLY, 2014). Dizendo de outra maneira, há uma prática de antimestiçagem oposta às teorias da miscigenação latino-americanas que defendem a dissolução do Múltiplo no Um (KELLY, 2014), pois parece-me que para os Mbyá a mistura/miscigenação é vista a partir do perigo da transformação.

Dessa forma, conforme vimos pela história de Kanuto, diferentes perspectivas não se somam - o que implicaria na miscigenação -, senão aparecem sempre como um valor dominante uma sobre a outra. Por isso o interessante parece sempre ser o devir, aquele que nunca se assemelha, mantendo a vertigem do quase (SZTUTMAN, 2013) para a relação com outros - sejam eles humanas ou nem tanto.

\section{Referências bibliográficas}

CADOGAN, León. Ayvu Rapyta: textos míticos de los Mbyá-Guarani del Guairá. Assuncion: Biblioteca Paraguaya de Antropologia, 1992.

CLASTRES, Pierre. A sociedade contra o Estado: pesquisas de antropologia política. São Paulo: Cosac Naify, 2003.

FAUSTO, Carlos. Donos demais: maestria e domínio na Amazônia. Mana, Rio de Janeiro, v. 14, n. 2, p. 329-366, 2008.

GOW, Peter. An amazonian myth and its history. New York: Oxford University Press, 2001.

HEURICH, Guilherme Orlandini. Outras alegrias: parentesco e festas mbya. 2011. 136 f. Dissertação (Mestrado em Antropologia Social) - PPGAS, Museu Nacional/UFRJ, Rio de Janeiro, [2011].

KELLY, José Antonio. State healthcare and Yanomami transformations: a symmetrical ethnography. Tucson: The University of Arizona Press, 2011.

The captive dominator and the becomer: an essay on criollo and indigenous mixture, change and social forms. Or about mestizaje and anti-mestizaje, 2014.

LÉVI-STRAUSS, Claude. A oleira ciumenta. São Paulo: Editora Brasiliense, 1986.

História de Lince. São Paulo: Companhia das Letras, 1993. 
NIMUENDAJU, Curt Unkel. As lendas da criação e destruição do mundo como fundamentos da religião dos Apapocúva-guarani. São Paulo: Hucitec/Edusp, 1987.

PIERRI, Daniel Calazans. O perecível e o imperecível: lógica do sensível e corporalidade no pensamento guarani-mbya. 2013. 275 f. Dissertação (Mestrado em Antropologia Social) - Departamento de Antropologia, USP, São Paulo, [2013].

PISSOLATO, Elizabeth. A Duracao da Pessoa: mobilidade parentesco e xamanismo mbya (guarani). 2006. 366 f. Tese (Doutorado em Antropologia Social) - PPGAS, Museu Nacional/UFRJ, Rio de Janeiro, [2006].

PRATES, Maria Paula. Dualidade, pessoa e transformação: relações sociocosmológicas mbyá-guarani no contexto de três aldeias no RS. 2009. $102 \mathrm{f}$. Dissertação (Mestrado em Antropologia Social) - PPGAS, UFRGS, Porto Alegre, [2009].

SEEGER, Anthony; DAMATTA, Roberto; VIVEIROS DE CASTRO, Eduardo. A construçao da pessoa nas sociedades indígenas brasileiras. Boletim do Museu Nacional, Rio de Janeiro, n. 32, p. 2-19, 1979.

SOARES, Mariana. Caminhos para viver o mbya reko. 2012. 320 f. Tese (Doutorado em Antropologia Social) - PPGAS, UFRGS, Porto Alegre, [2012].

SOUZA, José Otávio Catafesto de et al. Relatório de Diagnóstico do Potencial Arqueológico no trecho da Rodovia RS 330 entre a cidade de Derrubadas e o povoado de Pinheiro, municípios de Derrubadas e Tenente Portela (extensão de 9,6 km). UFRGS, 2010.

SOUZA PRADELLA, Luiz Gustavo. Entre os Seus e os Outros: horizonte, mobilidade e cosmopolítica guarani. 2009. 164 f. Dissertação (Mestrado em Antropologia Social) PPGAS, UFRGS, Porto Alegre, 2009a.

Jeguatá: o caminhar entre os guarani. Espaço Ameríndio, Porto Alegre, v. 3, n. 2, p. 99-120, 2009b.

SZTUTMAN, Renato. Metamorfoses do Contra-Estado. Ponto Urbe, Online, 2013. Disponível em: http://pontourbe.revues.org/893 . Acesso em: jun. 2015.

TEMPASS, Mártin. "Quanto mais doce, melhor": um estudo antropológico das práticas alimentares da doce sociedade Mbyá-Guarani. 2010. 395 f. Tese (Doutorado em Antropologia Social) - PPGAS, UFRGS, Porto Alegre, [2010].

VILAÇA, Aparecida. Making kin out of others in Amazonia. Journal of the Royal Anthropological Institute, v. 8, p. 347-365, 2002.

Chronically unstable bodies: reflections on amazonian corporalities. Journal of the Royal Anthropological Institute, v. 11, n. 3, p. 445-464, 2005. 
VIVEIROS DE CASTRO, Eduardo. A fabricação do corpo na sociedade xinguana. Boletim do Museu Nacional, Rio de Janeiro, n. 32, p. 40-49, 1979.

A inconstância da alma selvagem: e outros ensaios de antropologia. São Paulo: Cosac Naify, 2002.

Perspectival Anthropology and the Method of Controlled Equivocation. Tipití: Journal of the Society for the Anthropology of Lowland South America, v. 2, n. 1, USA, p. 3-22, 2004.

Posfácio. In: CLASTRES, Pierre (Org.). Arqueologia da violência: pesquisas de antropologia política. São Paulo: Cosac Naify, 2011. p. 296-361.

La mirada del jaguar: introducción al perspectivismo ameríndio - Entrevistas. Buenos Aires: Tinta Limón Ed., 2013.

WAGNER, Roy. A invenção da cultura. São Paulo: Cosac Naify, 2010.

Recebido em: 25/08/2015 * Aprovado em: 19/10/2015 * Publicado em: 31/12/2015 